\title{
O Laboratório Médico Prof. Alberto de Aguiar
}

\author{
Raquel Gonçalves-Maia* \\ Departamento de Química e Bioquímica, Faculdade de Ciências da Universidade de Lisboa \\ rmcgonc@gmail.com
}

\begin{abstract}
The Medical Laboratory Alberto de Aguiar - The Medical Laboratory Alberto de Aguiar is in Portugal a unique piece of its kind. Under a scientific point of view, its long history is exemplary for the quality of its research and services. But also exemplary since its foundation is the excellence of the interconnection between Science and Art it hosts - in stained glass and, especially, in friezes and panels shaped by the noblest Portuguese tile work. Regarded as a tribute, key figures of the world history of chemistry and medicine, and also professors of the Porto Faculty of Medicine (1886-1919), parade as tile medallions.

Alberto de Aguiar was a different man, he performed a remarkable enterprise conjuring immortality. In its own right the Medical Laboratory Alberto de Aguiar belongs to the cultural heritage of Humanity.
\end{abstract}

$\mathrm{O}$

Laboratório Médico Alberto de Aguiar é uma peça única do seu género em Portugal. A sua longa história do ponto de vista científico, pela qualidade da investigação e dos serviços prestados, é exemplar. Mas exemplar é, também, desde a sua fundação, a excelência da interligação entre Ciência e Arte que acolhe - em vitrais e, principalmente, em frisos e painéis da mais nobre azulejaria portuguesa. A título de homenagem, desfilam em medalhões de azulejos figuras incontornáveis da história universal da Química e da Medicina, e mestres da Faculdade de Medicina do Porto (1886-1919).

Alberto de Aguiar foi um homem diferente, executou obra notável e desejou-a imortal. O Laboratório Médico Alberto de Aguiar insere-se, por mérito próprio, no património cultural da humanidade.

\section{INTRODUÇÃO}

Foi em 1897 que nasceu o Instituto de Análises Clínicas, obra do Professor Alberto Pereira Pinto de Aguiar, em colaboração com o Dr. Joaquim Arantes Pereira. Funcionou até 1904 na antiga residência do primeiro, na Rua Elias Garcia ou D. Pedro IV, no Porto. Nesse mesmo ano, o Professor Alberto de Aguiar inaugura o Laboratório Médico (do Prof. Alberto de Aguiar), sito na Rua da Restauração, igualmente no Porto [1].

O mentor foi o grande químico português Professor António Joaquim Ferreira da Silva; e os patronos, os cientistas mundialmente famosos Antoine-Laurent de Lavoisier e Louis Pasteur.

Durante muitas décadas, mais de um século, o Laboratório Médico, primeiro sob a direção do próprio Professor Alberto de Aguiar, depois de sua filha e genro, os Drs. Alda Aguiar Côrte-Real e Eugénio Côrte-Real e, finalmente, dos Drs. Francisco do Carmo Pacheco e João Castro e Melo, tendo sido este posteriormente substituído pelo Dr. Augusto Machado, ofereceu pela qualidade e amplitude dos seus serviços, pela organização e funcionamento exemplares, pelo valor intrínseco dos seus diagnósticos, pela dedicação e entusiasmo sem limite dos seus membros, médicos e colaboradores, um serviço de excelência [1,2].

* Professora Catedrática aposentada
E de excelência foi, também, desde os primórdios da sua fundação, a disposição primorosa das suas instalações e a profusa, delicada e harmoniosa ornamentação, tanto das salas como, inclusive, dos boletins de análise. Em realce permanece a notável coleção de azulejos artísticos em frisos e painéis, na sua maioria da autoria do mestre pintor cerâmico Pedro de Figueiredo. A aliança entre Ciência e Arte que o Laboratório Médico Prof. Alberto de Aguiar transpira é única e notável. A ela prestaremos toda a atenção que indubitavelmente merece.

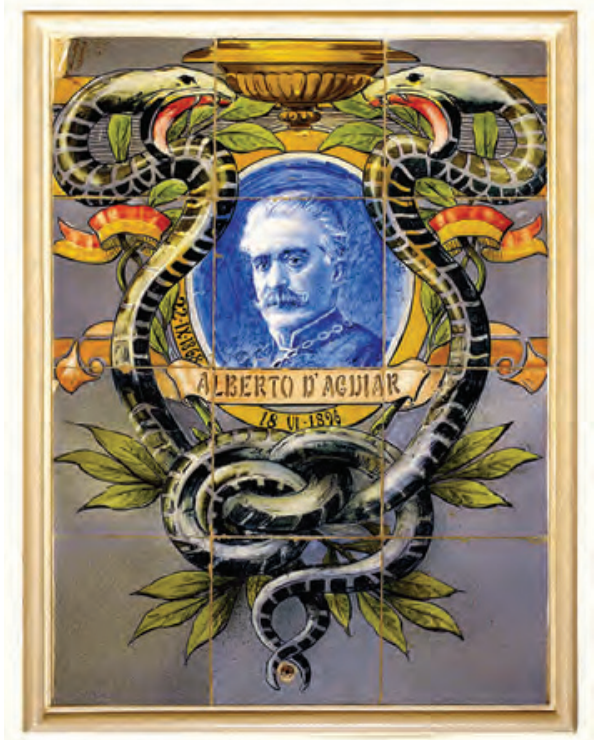

Figura 1 - Alberto de Aguiar, painel de azulejos de Pedro de Figueiredo, fotografia de Ângelo Sande - Laboratório Médico Prof. Alberto de Aguiar 


\section{O BERÇO FOI A QuímICA}

Natural de Cucujães, Oliveira de Azeméis, o Professor António Joaquim Ferreira da Silva (1853-1923) é figura incontornável no panorama científico português. Professor de Química na originariamente designada Academia Politécnica do Porto, depois Faculdade de Ciências (e Faculdade de Engenharia) da Universidade do Porto (1911), por muitos tem sido considerado "o maior químico português nas décadas de transição do séc. XIX para o séc. XX”; e, para outros, “o patriarca da Bioquímica portuguesa”.

A Ferreira da Silva se deve, entre múltiplos legados, numerosos trabalhos saídos de dias e noites de intenso trabalho no Laboratório da Academia [3], a direção comunicada ao Laboratório Municipal de Química do Porto (1883), a fundação partilhada da Academia das Ciências de Portugal (1907) [4] e a presidência, a primeira, da Sociedade Portuguesa de Química - SPQ (1911) [5,6]. Surge a publicação regular "Revista de Química Pura e Aplicada” em 1905; a "Revista Portuguesa de Química” e o “Boletim SPQ”, agora designado “Química”, são seus naturais sucessores.

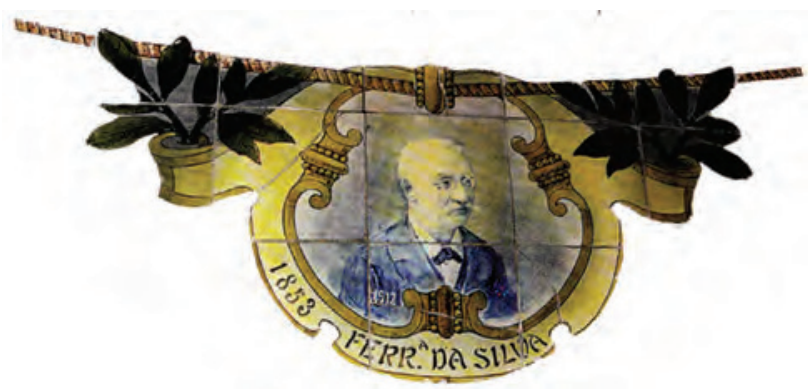

Figura 2 - Ferreira da Silva, medalhão de azulejos de Pedro de Figueiredo (1914), fotografia de Ângelo Sande - Laboratório Médico Prof. Alberto de Aguiar

Ferreira da Silva publica com regularidade. Da sua vocação de docente e investigador surgem tratados versando Química Analítica, Química Mineral, Química Orgânica, ... Interessa-se pela aplicação da Química à Medicina.

Facilmente se depreende que o apogeu da Química em Portugal se tenha centralizado no Porto, na figura de Ferreira da Silva, por pelo menos três décadas.

Data do mesmo período o apogeu de outra figura portuense, esta no campo de Medicina: Ricardo de Almeida Jorge (1858-1939).
O Dr. Ricardo Jorge foi professor de Medicina, investigador e higienista de ideias modernas - grande influenciador das modernas práticas de preservação da saúde pública. Era invulgar o seu talento multifacetado. Desvendava os segredos da Arte pictórica, da História, da Política e da Literatura - rival de Camilo no trabalho artístico da língua pátria, escreve Alberto de Aguiar [1].

Alberto de Aguiar foi, de tudo isto, testemunha e dinâmico interveniente, como veremos.

\section{A FundaÇ̃̃o do Laboratório MÉdico}

Alberto Pereira Pinto de Aguiar nasceu no Porto, em 1868. Em 1893 obtinha o seu grau de licenciado na Escola Médico-Cirúrgica do Porto e, três anos mais tarde, o de doutor. Entre 1896 e 1935, ano em que jubilou, leccionou na Universidade do Porto, na Faculdade de Medicina e na Faculdade de Farmácia, disciplinas de Bacteriologia, Parasitologia, Patologia Geral, Química Biológica e Fisiologia [6]. Tempos conturbados conduziram-no à fundação de um laboratório de análises particular, que veio a ser, ao longo de muitas décadas, um dos laboratórios de maior prestígio em Portugal; também aí a investigação teve o seu lugar $[1,2,7]$.

É o próprio Alberto de Aguiar que nos diz, no seu livro “Laboratório Médico" do Prof. Alberto de Aguiar curiosamente uma extensão do texto sobre o Laboratório feito propositadamente para a Exposição Internacional do Centenário da Independência do Brasil, que teve lugar no Rio de Janeiro em 1922 - que deve a orientação científica da sua vida profissional ao seu grande mestre Conc. ${ }^{\circ}$ Dr. António Joaquim Ferreira da Silva [1,7]. E mais afirma, em jeito de explicação, que foi a sua prática no Laboratório Municipal de Química do Porto, desde o seu 4. ${ }^{\circ}$ ano universitário (1891) até 1907, data em que o dito Laboratório foi extinto, que realizou trabalhos com vista à sua tese de licenciatura e candidatura ao professorado na Escola Médico-Cirúrgica do Porto.

Esta ligação mestre-discípulo, perdurará através de uma profunda amizade e admiração mútua. Que melhor testemunho poderíamos ter do que a oferta que Ferreira da Silva fez a Alberto de Aguiar de um apurado desenho de Louis Pasteur, assinado Édouard Lèon [8], com dedicatória escrita escassos seis dias antes de falecer?

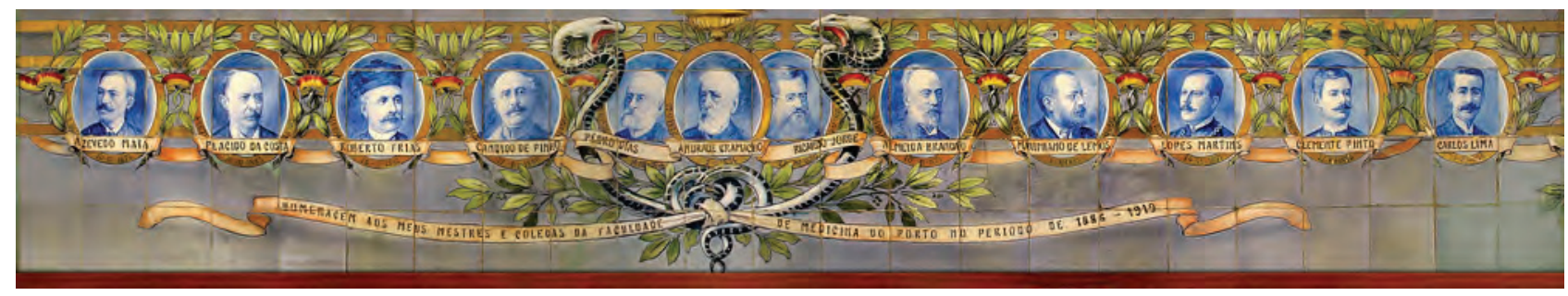

Figura 3 - Ricardo Jorge, ladeado por outros professores da Faculdade de Medicina da Universidade do Porto - período 1896-1916, painel de azulejos de Pedro de Figueiredo ( 1921 ), fotografia de Ângelo Sande - Laboratório Médico Prof. Alberto de Aguiar 


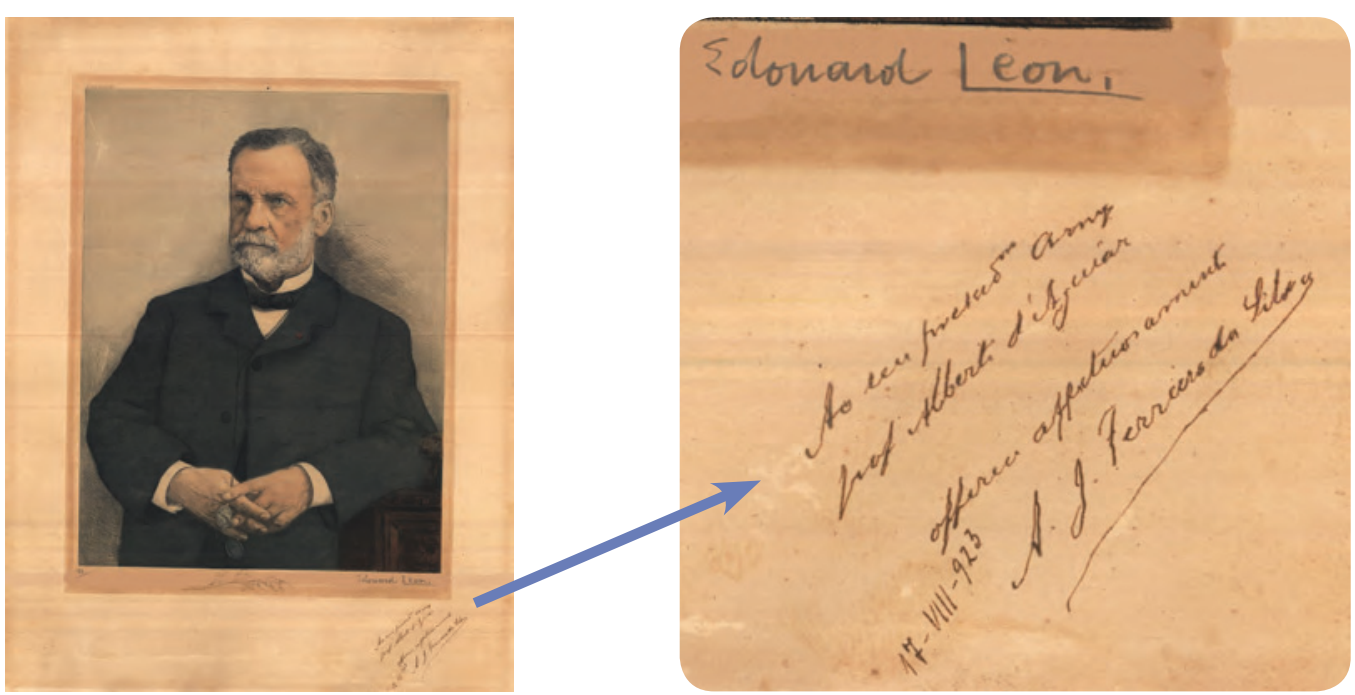

Figura 4 - Desenho de Louis Pasteur; pormenor da dedicatória

O desempenho de Alberto de Aguiar no Laboratório Nobre [9], vocacionado este para a execução de análises médicas, solidificaram a sua especialização. Assim, em conjunção com o Dr. Joaquim Arantes Pereira, criou o Instituto de Análises Clínicas. Depois, em 1904, Alberto de Aguiar inaugura o Laboratório Médico (do Prof. Alberto de Aguiar), sito na Rua da Restauração, igualmente no Porto [1,2].

Se o mentor da obra foi, nas próprias palavras de Alberto de Aguiar, Ferreira da Silva, os patronos do Laboratório Médico irão ser as figuras exemplares dos cientistas Antoine-Laurent de Lavoisier (1743-1794) e Louis Pasteur (1822-1895). Os seus bustos em bronze, colocados em destaque, velam pelas boas práticas dos profissionais. Não suficiente, mais tarde, o pincel e a arte cerâmica de azulejaria de Pedro de Figueiredo darão forma a dois grandes painéis decorativos, 1,55 m de altura por 1,94 m de largura, um representando Lavoisier no seu laboratório realizando a experiência típica sobre a composição do ar e, o outro, reproduzindo Pasteur a observar o resultado que o conduziu à descoberta da vacina antirrábica.
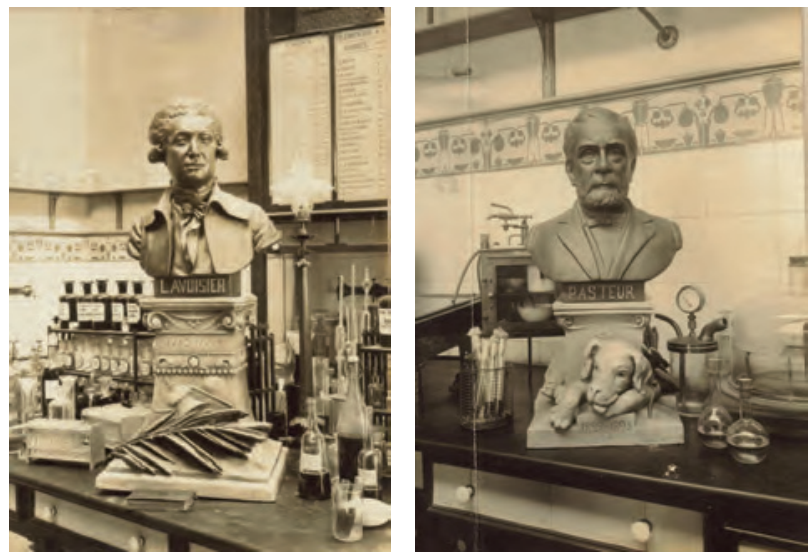

Figura 5 - Bustos de Lavoisier e de Pasteur - Laboratório Médico Prof. Alberto de Aguiar

\section{Reformas e AMPLIAÇÕES}

Nas mãos de Alberto de Aguiar, a pequena área inicial do Laboratório Médico foi sendo sucessivamente alargada e

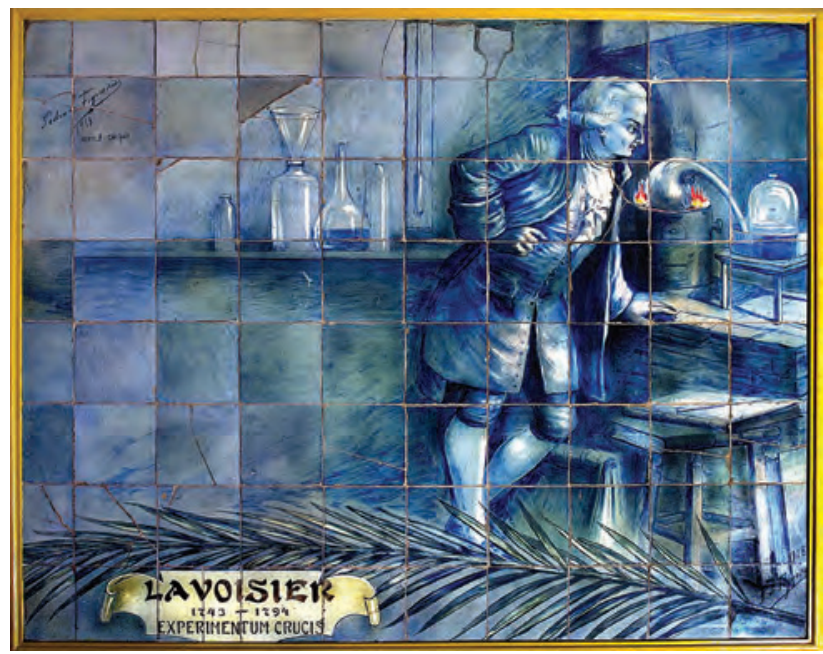

Figura 6 - Lavoisier, Experimentum Crucis, painel de azulejos de Pedro de Figueiredo (1918), fotografia de Ângelo Sande - Laboratório Médico Prof. Alberto de Aguiar

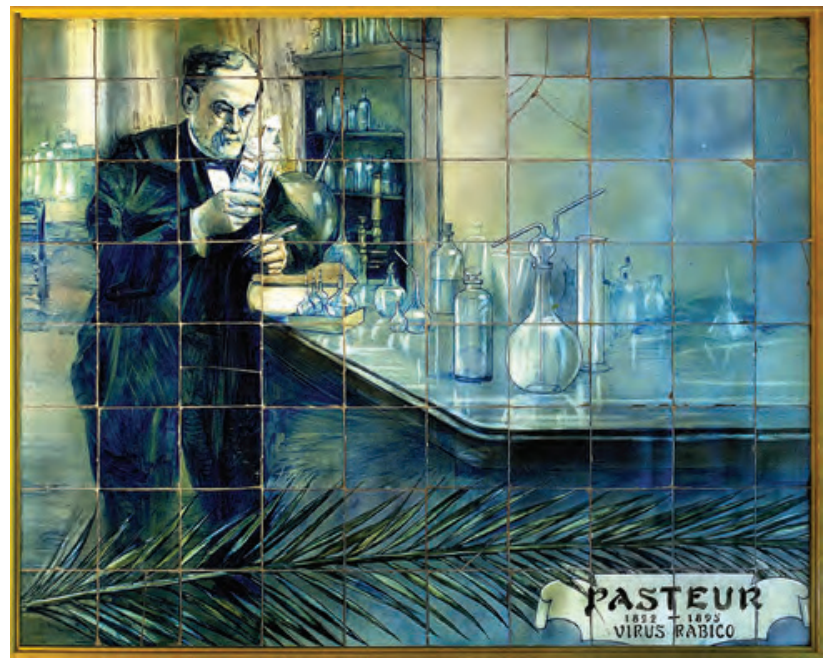

Figura 7 - Pasteur, Virus Rabico, painel de azulejos de Pedro de Figueiredo (1918), fotografia de Ângelo Sande - Laboratório Médico Prof. Alberto de Aguiar

reestruturada, principalmente em 1908, 1914 e 1921; sofreu igualmente alterações de cariz artístico de grande relevância. 
Após 1914, a área ocupada pelo Laboratório Médico foi de cerca de $400 \mathrm{~m}^{2}$, dispostos em três pisos e um anexo. Para além de salas de recepção e de consulta, gabinete, biblioteca e depósitos, dispunha de laboratórios de Química, Bacteriologia, Serologia, Microscopia e Microfotografia, coadjuvados por um gabinete de balanças, estufas, zona de lavagem de material e um quarto escuro.

Uma fotografia datada de 1914, Figura 8, mostra-nos Alberto de Aguiar e os seus colaboradores na área laboratorial, propriamente dita [10]. Repare-se nos dois frisos de azulejos que ornamentam as paredes, um quase tocando o teto e outro, mais estreito, a meia altura na parede. Reproduzimos neste artigo parcelas de ambos.

No primeiro é visível uma mescla de algas, cadinhos e vasos florentinos entrelaçados numa fita que expõe, cronologicamente, nomes e datas de nascimento e morte de vinte e oito personagens que muito se distinguiram na história na

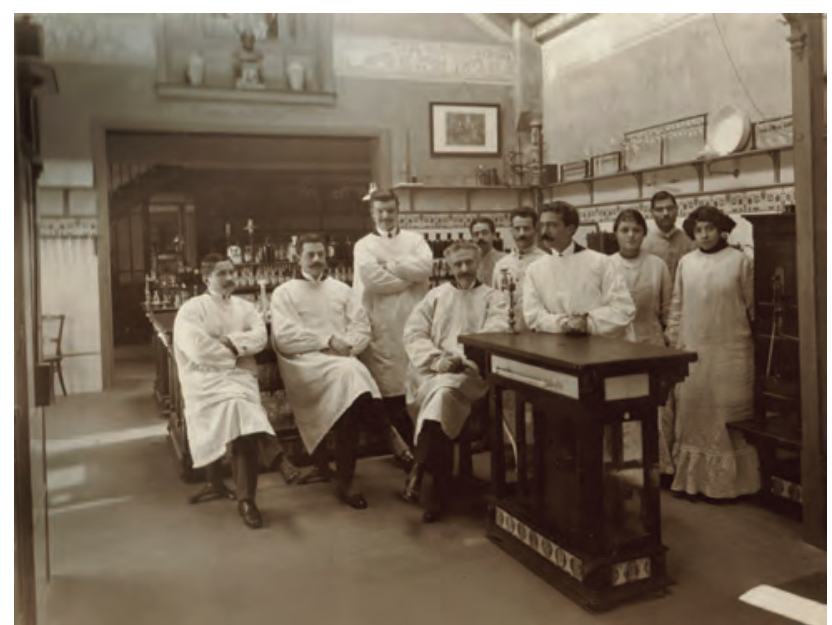

Figura 8 - Alberto de Aguiar e seus colaboradores - 1914 (António Guimarães, Martins Barbosa, Rocha Pereira, Carlos Ramalhão e pessoal auxiliar) - Laboratório Médico Prof. Alberto de Aguiar
Alquimia/Química - desde Zósimo de Panópolis e Sinésio de Cirene (séc. IV) até aos galardoados com o Prémio Nobel Henri Moissan e van’t Hoff, passando por Antoine Lavoisier, Justus von Liebig, Adolphe Wurtz, Sainte-Claire Deville e Victor Meyer entre outros. Diz-nos Alberto de Aguiar, que o desenho deste friso se deve ao notável professor de desenho artístico van Krieck, artista que não conseguimos identificar.

No segundo friso reina o material de laboratório - retorta, forno de combustão, cadinho, cápsula e o Kaliapparat num arabesco pictórico de enorme graciosidade, muito ao gosto da época; a ele nos referimos com pormenor em artigo publicado no Boletim da SPQ, Química [11].

A qualidade e quantidade dos serviços analíticos prestados nos primeiros anos de funcionamento do Laboratório Médico podem ver-se no arquivo organizado no Boletim Trimestral do Laboratório (até 1909) e na Revista de Semiótica Laboratorial (1910-1917).

O detalhe a que Alberto de Aguiar tudo submetia mostra uma organização notável: o pessoal de laboratório, médicos, auxiliares e escriturários, com a competência indispensável nas diferentes secções científicas, os registos de entradas, os verbetes para arquivo de resultados analíticos, os impressos analíticos, o preçário, as instruções, os boletins médicos...

Um exemplo de modelo de vinheta dos boletins analíticos, destinado a análise de urina, apresenta-se na Figura 11. Assinado "Hugo" e datado "1905" é uma amostra raríssima onde a profusão de material e de experiências químicas de laboratório - reagentes, buretas, balanças, fornalhas, alambiques, destilações, ... inundam um desenho minucioso, onde a surpresa e a admiração exigem contemplação demorada.

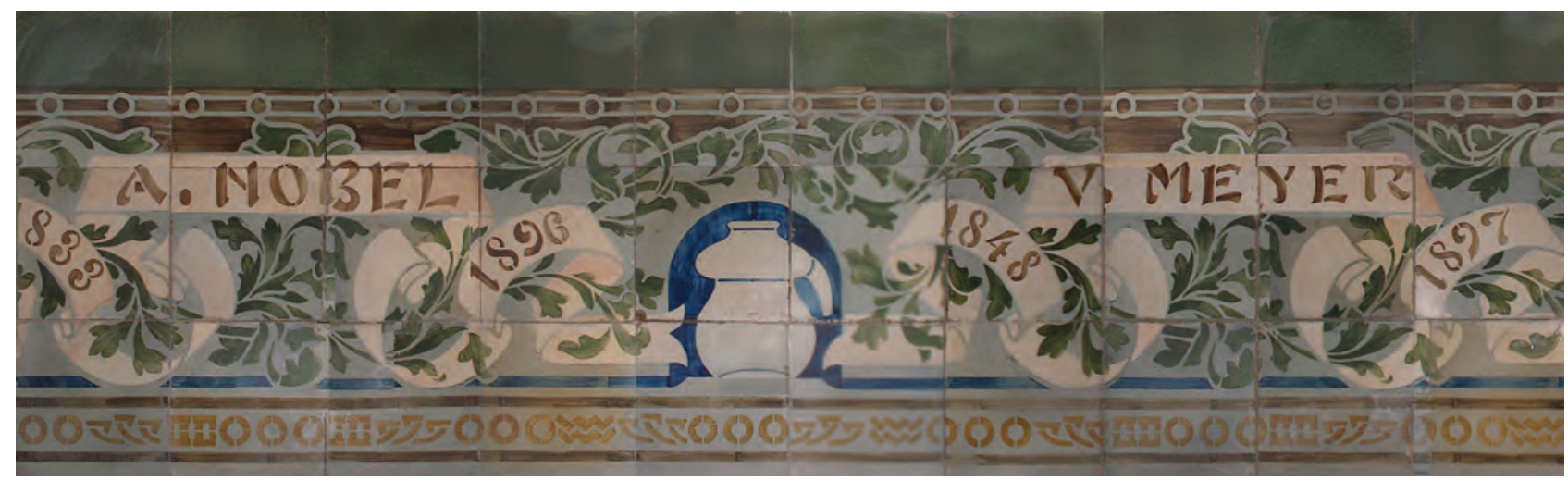

Figura 9 - Parcela do friso contendo os nomes de grandes vultos da Química (reconstituição) - Laboratório Médico Prof. Alberto de Aguiar

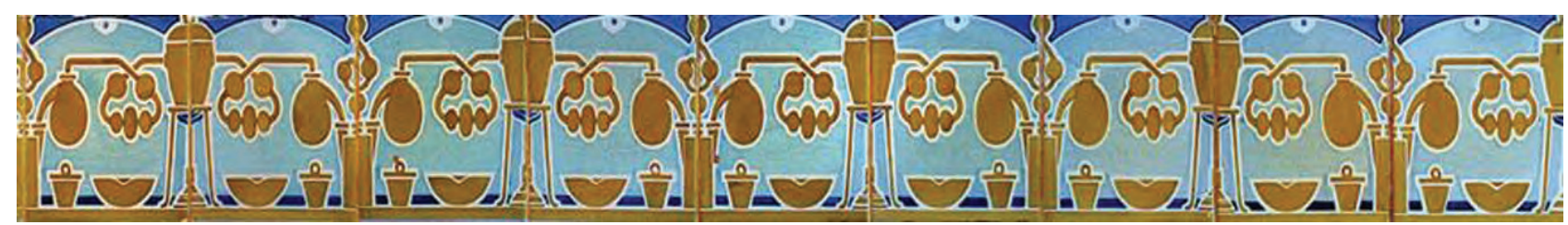

Figura 10 - Parcela do friso contendo desenhos de material de laboratório, fotografia de Ângelo Sande - Laboratório Médico Prof. Alberto de Aguiar 
Para além do indiscutível valor científico que o Laboratório sempre apresentou, o valor artístico adicional que lhe foi conferido, tornou-o único em Portugal, senão no Mundo.

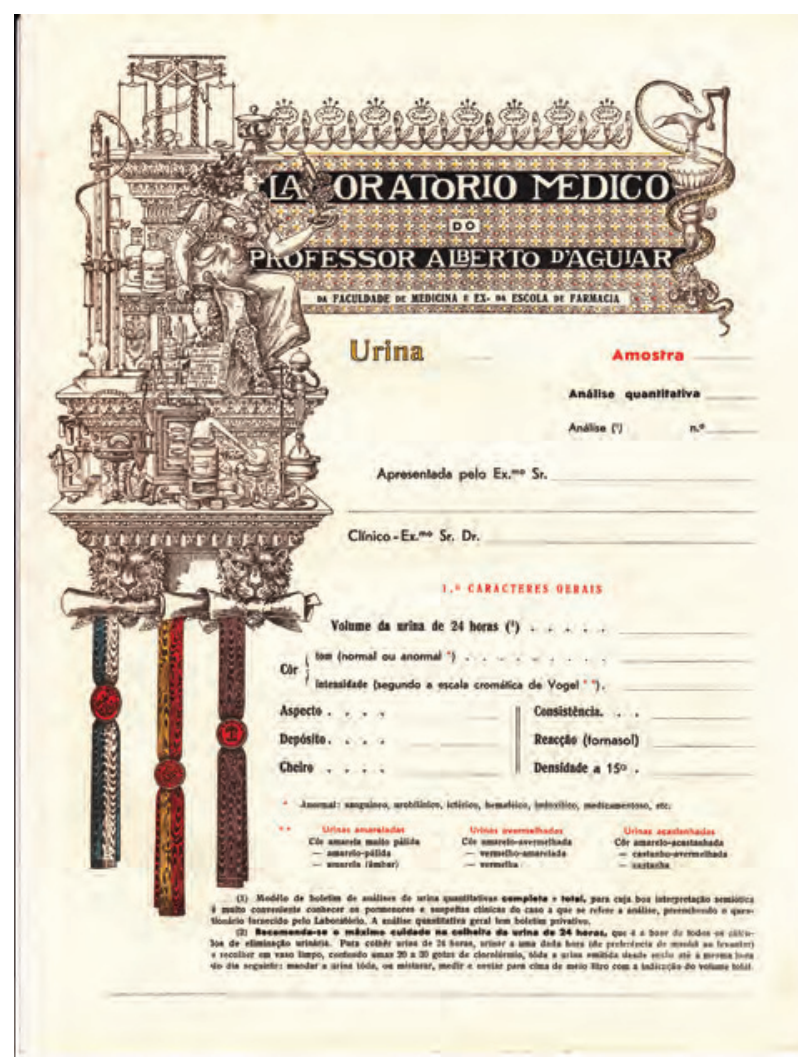

Figura 11 - Modelo de vinheta de boletim analítico ( $1^{\text {a }}$ página $)$ - análise de urina - Laboratório Médico Prof. Alberto de Aguiar

\section{Arte e Clência}

Quando a Ciência encontra a Arte, assim ou ao inverso, estabelece-se uma simbiose interdisciplinar cujo resultado suplanta a soma das partes.

Referimos já os painéis de azulejos que reproduzem, em pintura cerâmica, as experiências cruciais de Lavoisier e de Pasteur (Figuras 6 e 7); e os elegantes e ornamentais frisos, igualmente em azulejo que bordejam o teto e separam a parte superior das paredes, em estuque, da parte in-

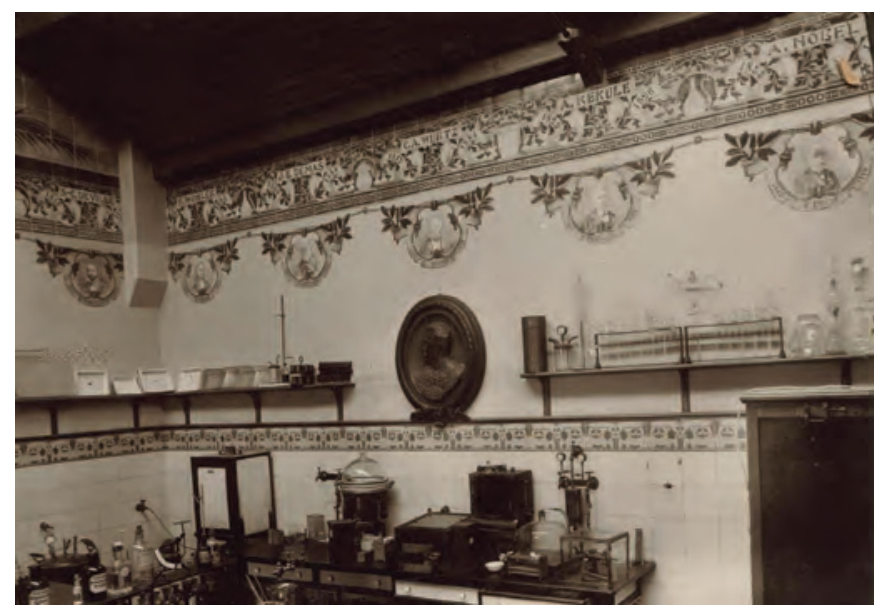

Figura 12 - Recanto do Laboratório mostrando fragmentos dos diversos frisos ferior, em azulejo branco, onde material de laboratório e a evocação do nome de cientistas que deram voz à Química/ Medicina têm relevo (Figuras 9, 10 e 12).

No grande laboratório, um grupo de azulejos policromados, da autoria do artista Pedro de Figueiredo, desenha ainda um outro friso em grinalda, ornamentada de folhagem, de onde pendem dezanove medalhões com os retratos de vários químicos e médicos de renome, nacionais e estrangeiros (Figura 12): Ferreira da Silva (Figura 2), Vicente Lourenço, Câmara Pestana, Justus von Liebig (Figura 13), Friedrich Wöhler, Jean-Baptiste Dumas, August Kekulé e Alfred Nobel, por exemplo [12].

E acrescente-se à riqueza da azulejaria, os vitrais policromados que difundem em colorido irresistível a luz filtrada no laboratório.

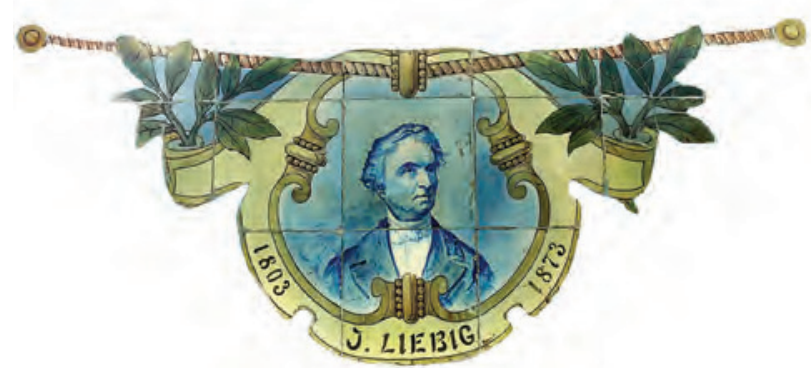

Figura 13 - Justus von Liebig, medalhão de azulejos de Pedro de Figueiredo ( $\approx 1914)$, fotografia de Ângelo Sande - Laboratório Médico Prof. Alberto de Aguiar

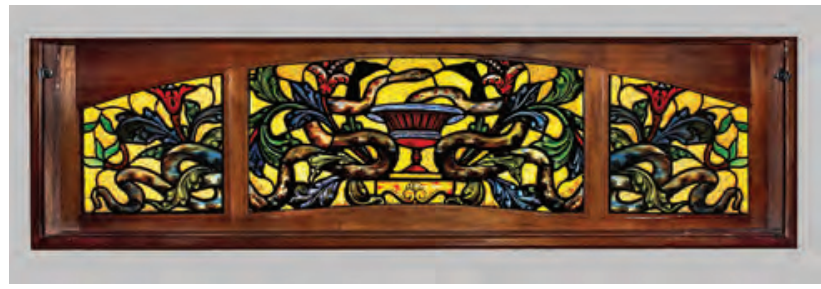

Figura 14 - Vitral da Biblioteca do Laboratório Médico

Em 1921, Alberto de Aguiar, com uma larga assistência composta, principalmente, por colegas e amigos convidados, inaugura um novo friso, em seis segmentos, uma homenagem sentida à Faculdade de Medicina do Porto, aos seus mestres e companheiros de estudo. São trinta e nove os professores e clínicos retratados em medalhões magnificamente decorados - onde as serpentes médicas e os mochos sábios têm particular destaque; um dos segmentos (Figura 1) retrata, em exclusivo, o Professor Alberto de Aguiar. É, no seu conjunto, uma obra admirável. À sua inegável importância científica e artística, passado que foi mais de um século sobre a sua execução, deve juntar-se a relevância para a História da Ciência em Portugal (da Medicina Laboratorial e da Química, em particular).

Algumas palavras biográficas são devidas ao pintor e retratista cerâmico Pedro de Figueiredo. Pedro de Figueiredo (Ferreira) nasceu em Tondela em 1880. Cursou a 

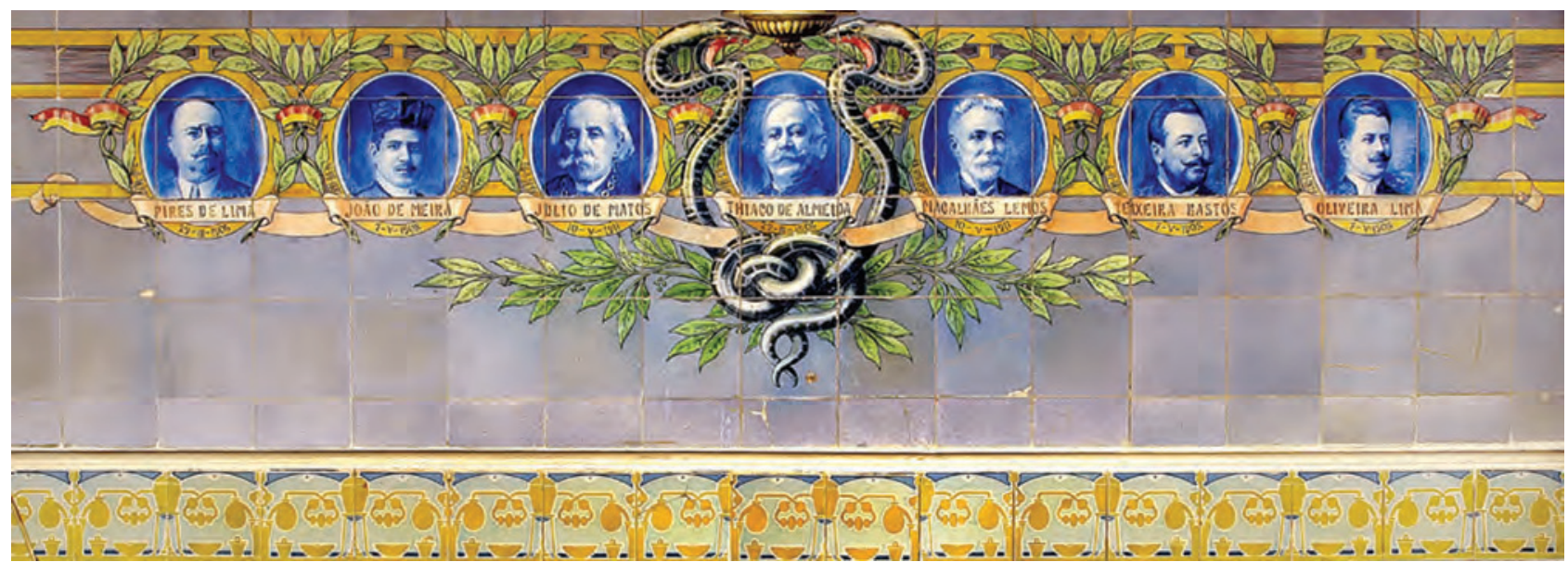

Figura 15 - Professores da Faculdade de Medicina da Universidade do Porto - período 1896-1916, painel de azulejos de Pedro de Figueiredo ( $\approx 1921$ ), fotografia de Ângelo Sande - Laboratório Médico Prof. Alberto de Aguiar

Academia Portuense de Belas Artes e, depois, rumando a Paris, a Académie de la Grande Chaumière; mas foi Jorge Colaço, um dos maiores vultos da azulejaria portuguesa, a influência mais significativa na sua formação.

Foi professor na Escola Faria Guimarães, a atual Escola Secundária Artística de Soares dos Reis, no Porto. Deixou uma vasta obra, onde se destacam os painéis decorativos do átrio da Câmara Municipal de Tondela e, sem dúvida, os painéis e frisos que adornam o Laboratório Médico. Veio a falecer no Porto em 1972.

\section{A passagem DE TESTEMUNHO}

Alberto de Aguiar, pioneiro da Medicina Laboratorial, foi um profissional de perfil irrepreensível, sempre a par da evolução do conhecimento teórico, prático e técnico-científico. Um dia, porém, foi tempo de "passar o testemunho". Corria o ano de 1938.

Sua filha Alda Borges de Aguiar licenciara-se em Medicina em 1936 e casara com o seu colega de curso Eugénio Saraiva Côrte-Real [13]. Serão eles os continuadores da obra.

O Laboratório Médico, sob a direção do Doutor Eugénio Côrte-Real, manterá um elevado padrão de qualidade de serviços.

Tal como o seu sogro, Côrte-Real era um homem austero, exigente com todo o pessoal de laboratório e, muito mais ainda, consigo próprio. Mas, para quem o conheceu de perto, sabe que era possuidor de uma forte sensibilidade e vocação artística [2,13]. Pintava e a sua pintura é obra de uma vocação iniludivel. Não admira, pois, que a preservação do Laboratório Médico, também do ponto de vista artístico-patrimonial, tenha sido uma sua constante preocupação. Preocupação exemplar que transitou para os diretores que se seguiram, até ao fecho do Laboratório, em 2009.

O edifício, que ostenta na sua face os dizeres "LABORATÓRIO MÉDICO” em pedra corrida sobre a tripla porta de entrada e, em ferro forjado, numa das portas "PROF. A.
AGUIAR”, ainda está de pé. E o seu espólio, de talento e arte feito, em grande parte conservado.

O sol da foz do Douro invade o varandim, abre as grandes janelas do espaço laboratorial e inunda de luz uma preciosidade que Portugal teima em desconhecer. Há uma sublimidade que não pode ser ignorada, que não se pode esconder da História. A homenagem justa e perene tem de surgir em muito mais do que um livro ou um simples artigo. Há uma exigência moral na conservação deste património único da Humanidade.

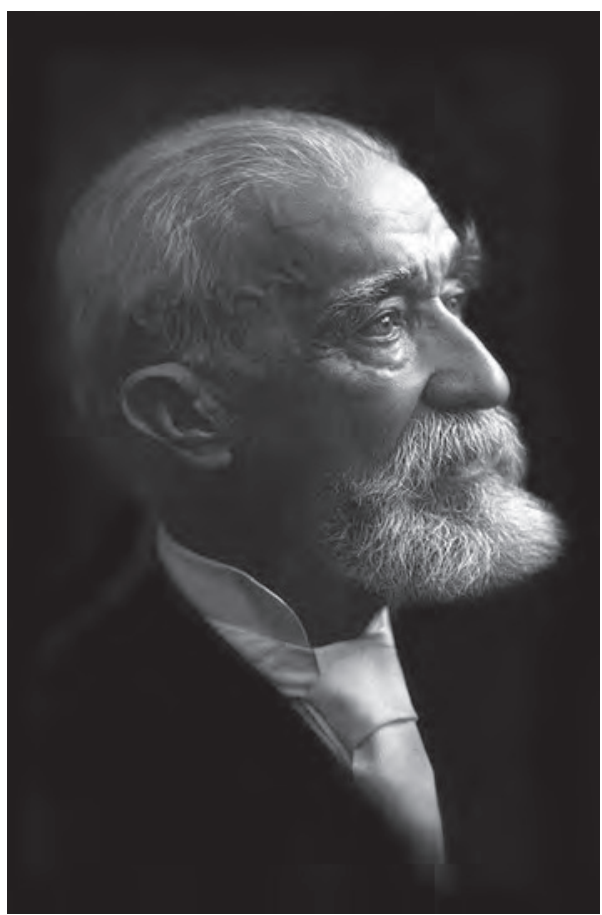

Figura 16 - Professor Alberto de Aguiar ( 1940$)$

\section{AgRAdECIMENTOS}

A feitura deste artigo só foi possível graças à prestimosa colaboração de José Pedro Aguiar Côrte-Real, neto do Professor Alberto Pereira Pinto de Aguiar e de D. Isabel Maria de Carvalho Borges, sua mulher, e filho dos Drs. Eugénio Saraiva Côrte-Real e Alda Borges de Aguiar Côrte-Real, 
que facultou o nosso acesso às instalações do Laboratório Médico e nos ofereceu depoimentos e muitas das fotografias, originais, que ilustram este artigo.

O nosso agradecimento vai também para Eduardo Alberto Aguiar Botelho de Souza (Rio de Janeiro) e Maria Cristina Aguiar de Albuquerque Cardoso Trigueiros (Porto), ambos netos do Professor Alberto de Aguiar, pelas úteis informações prestadas e cedência de algumas fotografias.

A Francisco do Carmo Pacheco muito agradeço a primeira visita guiada ao fascinante património científico e artístico do Laboratório Médico.

A Jorge Teixeira (Portojo) e Alice Santos (Biblioteca Central, FMUP) desejo agradecer a prontidão de resposta às minhas solicitações.

\section{REFERÊNCIAS}

[1] A. de Aguiar, $O$ "Laboratório Médico" do Prof. Alberto de Aguiar, tip. Mendonça, Porto, 1922

[2] F.C. Pacheco, Um Século de Medicina Laboratorial. O Laboratório Médico Prof. Alberto de Aguiar, Ordem dos Médicos - Conselho Regional do Norte, Porto, 1998

[3] O "Laboratório Químico da Escola Politécnica do Porto" dará lugar ao "Laboratório Químico da Faculdade de Ciências do Porto" e, mais tarde, em homenagem, ao "Laboratório Ferreira da Silva” da Universidade do Porto

[4] A Academia das Ciências de Portugal foi uma instituição académica, de cariz republicano, com existência entre 1907 e 1925, visando estimular a ciência e a divulgação científica; era constituída essencialmente por intelectuais que se sentiam excluídos da Academia (Real) das Ciências de Lisboa

[5] J.F. Alves e R.C. Alves, “A.J. Ferreira da Silva - Nos Caminhos da Química”, U. Porto Editorial, Porto, 2013

[6] Em "Antigos Estudantes Ilustres da Universidade do Porto”. http://sigarra.up.pt/up/pt/web_base.gera_pagina?P_pagina=1006517 (acedido a 16-05-2015)

[7] Na majestosa Exposição Internacional do Centenário da Independência do Brasil, Portugal foi o único pais “estrangei- ro”, a dispor de dois pavilhões, estando um deles, o mais pequeno, situado na zona dos pavilhões nacionais. O grande Pavilhão de Portugal (um dos poucos sobreviventes) foi reconstruído no Parque Eduardo VII, em Lisboa, e constitui o atual Pavilhão Carlos Lopes, cuja profunda degradação tem sido alvo de acesas discussões na Câmara Municipal de Lisboa; recentemente, foi prevista a sua requalificação como centro de congressos (Novembro, 2014).http://www. cm-lisboa.pt/noticias/detalhe/article/orcamento-2015-mantem-baixa-carga-fiscal

[8] O desenho primoroso é, quase certo, obra do reconhecido botânico francês Philippe Édouard Léon Van Tieghem (1839-1914) que trabalhou durante algum tempo no laboratório de Pasteur

[9] O nome do "Laboratório Nobre” honra o benemérito Bruno Alves Nobre que, em testamento, doou "[...] 80 contos, com a obrigação da dita Escóla [Escola Médico-Cirúrgica do Porto] custear, com doze mil reis mensaes, a educação, até completa formatura, de doze pensionistas pobres" (1891). http://sigarra.up.pt/fmup/pt/uni_geral.unidade_ view?pv_unidade=189 http://gisaweb.cm-porto.pt/unitsof-description/documents/10346/ (acedido a 16-05-2015)

[10] Alguns dos filhos de Alberto de Aguiar foram seus colaboradores: Álvaro de Aguiar, o filho mais velho, que teria sido o seu natural sucessor na direção do laboratório, não fosse o facto de ter falecido, tragicamente, vítima de febre tifoide contraída durante uma análise efetuada a um doente portador da doença [2]; Maria Isabel de Aguiar (escriturária); Ilda Borges de Aguiar (diplomada em Farmácia); e, ainda, Alda Borges de Aguiar, médica, sobre quem recaiu, conjuntamente com o marido, os destinos do Laboratório Médico

[11] R. Gonçalves-Maia, Química 137 (2015) 53-59

[12] Existe outro painel de azulejos, há muito retirado do laboratório, onde foram representados os principais animais utilizados como cobaias no laboratório; escreve Francisco do Carmo Pacheco que tal painel está conservado e que foi mesmo presente a público "numa mostra sobre azulejaria do Porto, no Pavilhão do Mercado Ferreira Borges” [2]

[13] F.C. Pacheco, Doutor Eugénio Côrte-Real, Figuras da Medicina, Medicina Interna 4(2) (1997) 137-140. http://www. spmi.pt/revista/vol04/vol04_n2_1997_137-140.pdf (acedido a 16-05-2015)

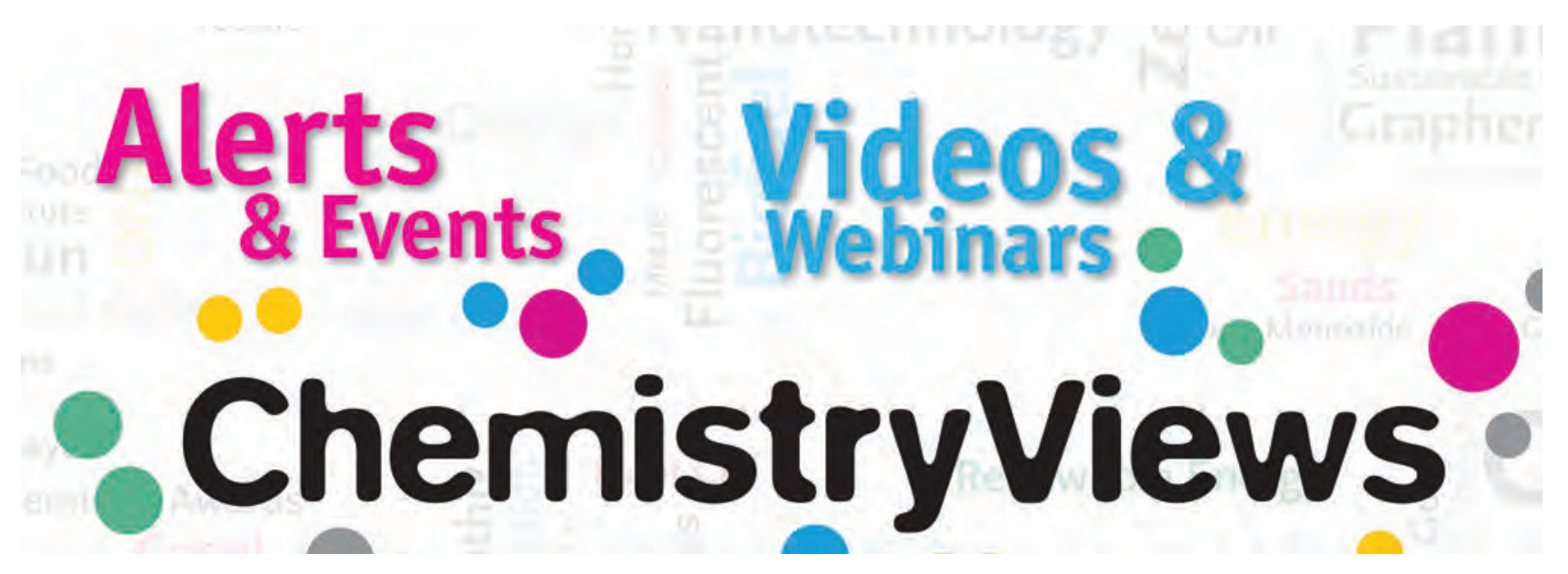




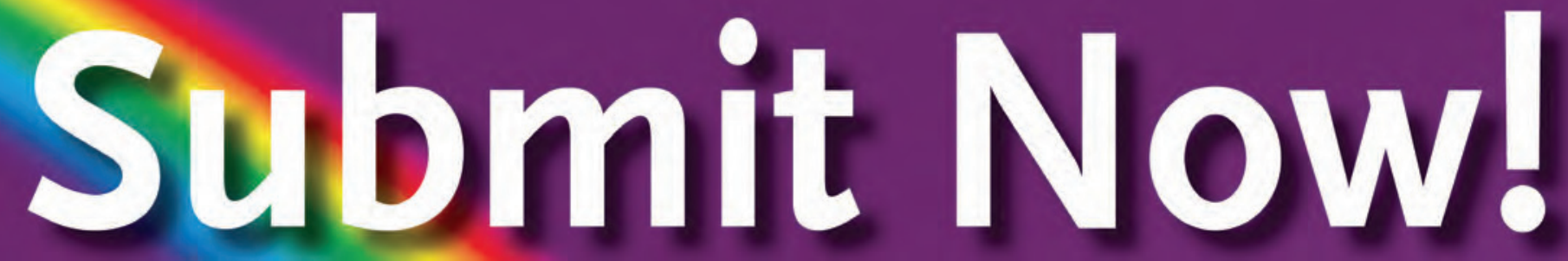

ChemistryOPEN is one of 11 journals of ChemPubSoc Europe an organisation comprising 16 European chemical societies. www.chempubsoc.eu

\section{Editorial Advisory Board} Chairmen:

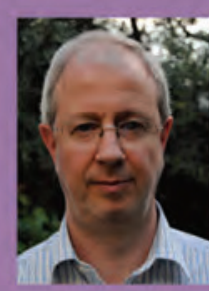

\section{Martínez-Máñez,}

Polytechnic University

of Valencia, Spain

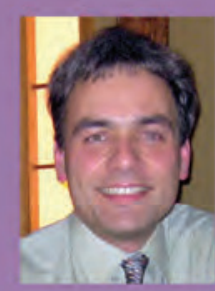

Thomas Wirth,

Cardiff University, UK

Editorial Advisory Board Honorary Chairman:

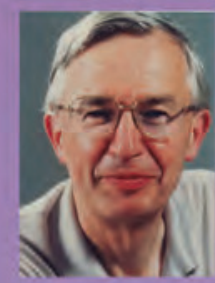

Jean-Marie Lehn, Nobel Prize winner in chemistry in 1987 , Collège de France, Paris / Univ. L. Pasteur, Strasbourg, France

A journal of

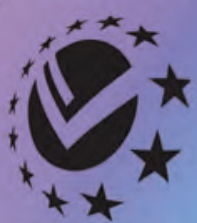

ChemPubSoc Europe

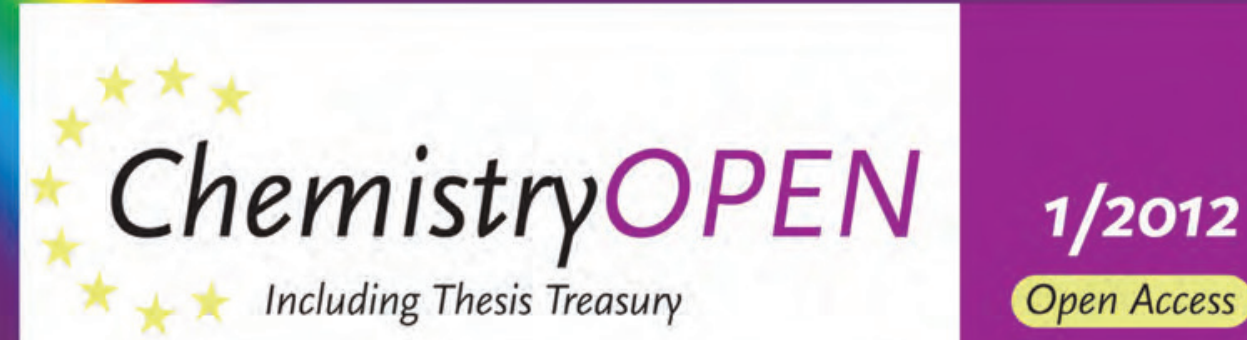

The first society-owned open access chemistry journal

A Journal of

\section{Call for Papers}

(2)WILEY-VCH

(W)WILEY Open Access

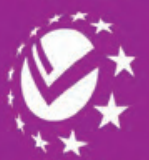

ChemPubSoc Europe

\section{www.chemistryopen.org}

